\title{
Recovery of Human Values through Mathematics Education for Social and Economic Development in Nigeria
}

\author{
Chinweoke, Felicia U. \\ Science Education Department, Chukwuemeka Odumegwu Ojukwu University, Anambra State
}

\begin{abstract}
Human values are vital for the enhancement of social and economic development in a country especially Nigeria. This paper tries to $X$-ray recovery of human values through mathematics education for social and economic development in Nigeria. Mathematics education and some aspects of human values such as self-discipline, problem-solving and diligence (hard work) which mathematics education inculcates in the children are looked into; with the implications that if mathematics education is properly carried out in the families, schools and society at large the lost glory of human values is sure to be recovered. Above all, peace and freedom should take their rightful place in the society for and there will be great improvement in the social-economic development in Nigeria. So, governments and educational stakeholders such as parents, teachers and other bodies in education should perform their duties properly to enhance social and economic development in Nigeria.
\end{abstract}

Keywords: Prior knowledge, Behavioural Objectives, Study Questions, Mathematics, Studentss

\section{Introduction}

Education is the gate way to socio-economic development of any country. Education (particularly, mathematics education) is the soul of a society, a people, and a nation. Its quality is therefore a huge determinant of the height a nation can attain or the depths to which it can descend as regards to scientific and technological development. Education in the real sense of it is the awakening of human mind to the realities of its immediate environment, the challenges that need to be overcome and the opportunities that can be exploited. The right education should provide one with the skills to function and participate in Society, both as an individual and as a member of that society (Nwobi, 2015). Fufunwa (1982) stated that education is a process for transmitting culture in terms of continuity and growth or to generate rational direction of the society or both.

Education is concerned with development of all faculties of a child; physically, mentally, psychologically, spiritually etc. Education sees to the formation of children into human persons committed to work for the creation of human communities of love, fellowship, freedom, justice and harmony (Parankimalil, 2012). One of the national goals of education is the inculcation of the right type of values and attitudes for survival of the individual and the Nigerian society (Federal Republic of Nigeria, FRN, 2004). Some aspects of the purposes of primary education are to provide sound basis for scientific and reflective thinking and to provide development in character and moral training and sound attitude in the children. These have shown that Federal government is also concerned with the recovery of human values for socio-economic development of the country Nigeria.

Values are generally regarded as those things that are good in themselves. Values are the believes of man that guides his ethics and choice. Human values in the other hand are the habits or thought one acquires as one grows from childhood to adulthood which enables one assess and deal with things that are right or wrong. Human values are the principles, standards, convictions and belief that people adopt as their guidelines in daily activities (Steriner, 2012). Grain of Peace Values (2010) pointed out that human values are the foundations for any viable life within the society which build space for a drive and movement towards one another that leads to peace as well as freedom. Some of these human values are love, honesty, hard word (diligence), peace, openness, loyalty (respect), friendship, kindness, justice, fairness, discipline, problem-solving, care for one another and being mindful of the environment etc. Some of these human values can be achieved or attained through mathematics education such as spirit of hard work, problemsolving and self-discipline.

\section{Mathematics Education}

Mathematics education is the right education by which social and economic development can be achieved through inculcation of right human values in the children. Mathematics education is concerned with the teaching and learning of mathematics in the classrooms and outside the classrooms. One of the objectives of secondary school mathematics is to enable the individual to think creatively and constructively. Mathematics since its invention has influenced positively the culture and thought of various nations and has in no small measure helped in revolutionalising the world (Onwudinjor and Onwudinjor, 1999).

Agwagah (2005) pointed out that mathematics is an essential part of human culture, which the educational system is designed to transmit. Mathematics is the best way to teach youngsters how to think. The volume and quality of mathematics offered in the school system determines the prosperity of any country (Awodeyi, 2004). Harbour-Peters (2000) saw mathematics as a culture which affords man the opportunity to known and access things and objects within his immediate and remote environment. Kolawole and Oluwatayo (2005) pointed out that mathematics through 


\section{International Journal of Science and Research (IJSR) \\ ISSN (Online): 2319-7064 \\ Index Copernicus Value (2013): 6.14 | Impact Factor (2014): 5.611}

careful and logical thinking can be used to solve human problems in all spheres of life. Mathematics through reasoning can give insight into the power of human mind. All these attributes of mathematics are highly essentials in the recovery of human values in the areas of diligence (hard work), problem-solving and self-discipline.

Diligence: One of the attributes of human values is diligence (hard work). In the olden days, people work very hard in pursuit of daily living. Nowadays, the syndrome of get rich quick is the order of the day which has killed the spirit of hard work in our youths. This is because our children are no longer interested in learning talkless of learning mathematics which they see as a logical subject (Nwameradi, 2005) and abstract in nature (Salau, 2002) and too difficult to learn. The children of nowadays do not want to engage themselves in anything that involves hard work, they just want quick access to everything. This is why they involve themselves in examination malpractices and miracle centre of a thing to pass their examinations. This has so many negative influences on the society. Crimes are at increase due to lack of spirit of hard work in our children. There are many cases of armed robbery, corruption, kidnapping, sexual abuse, prostitution etc. Agonga (2011) posited that there are many crimes in the society today due to lack of human values. All these evils have negative impact on Nigeria societies today. The president of Nigeria Muhammadu Buhari lamented on the problems of insurgency, militancy, armed robbery, kidnapping and other social ills and posited that the activities of these misguided groups and individuals have resulted in wanton destruction of our citizens as a disruption of social and economic lives of millions of Nigeria (TaiwoObelonye, 2015). In fact, Nigeria needs moral regeneration (Okoye, 2012) which could be possible by recovery of human values through mathematics education.

Mathematics properly inculcated at early stage of child's development may help the child to develop the spirit of hard work in future and teach them that there is dignity in labour. This is because mathematics enthuses an individual who engages in it into working diligently to arrive at correct answer to a problem. In this way any child who develops the spirit of diligence in solving correctly any mathematical problems can as well adopt the same spirit in solving future problems. Kolawole and Oluwatayo (2005) pointed out that mathematics is primarily concerned with the methods of discovery certain truths and the nature of the truths so discovered is achieved through the spirit of hard work.

Self- Discipline: Discipline is an act of controlling ones emotion and temperament. Mathematics helps in disciplining of oneself and mind. Mathematics is a character molder. This is because mathematics processes play great role on how one looks at certain issues in life and the way one takes precautions in viewing things, taking presumptions and hypotheses before jumping at judgment or conclusions. Moore 2003) posited that mathematics is useful at an intellectual level, one obviously gain from going through a rigorous course in mathematics education. Mathematics is clarity, logicality and succinctness of thought and articulacy. Mathematics inculcates in its students discipline, problemsshooting attitude, tenacity and doggedness, confidence, the penchant for always seeking the optimal way of doing things, the disposition to always face challenges squarely and a suspicion of intuition simplicties (Moore, 2005). So, mathematics it properly taught to students (children) obviously may bring out all these qualities in them which may help in disciplining their minds. Mathematics education is a vital avenue for achieving self discipline in children and self discipline is one of the means for attaining socioeconomic development in Nigeria.

Problem- Solving: Mathematics is a subject that trains the mind through problem-solving. This it does through development of critical thinking and rational reasoning. Agwagah (2005) emphasized that critical thinking involves careful steps such as making definite statement or at least consideration of assumptions, a knowledge of the meaning and procedures of inductive reasoning, the ability to make logical inference, the ability to recognize logical fallacies both in one's own work and in the work of others. The ability to know that the proof or solution of a problem is complete and finally that the correctness of any solution is dependent on the assumptions and the validity of solutions of dependent problems or theorems. The process of thinking and reasoning are engaged in the process of mathematical problem-solving and thus training in the processes of mathematical problem- solving provides training in reasoning and critical thinking. Thus mathematics education is highly essential in the development of critical thinking and rational thinking in an individual as that may help an individual in calculating and assessing his/her actions before carrying them out. This follows from the view point of Agwagah (2005) that mathematics involves all the critical thinking abilities, which include analytical reasoning, reflective thinking, inductive thinking and deductive reasoning which the learning of mathematics should develop in the learner. The role of teacher in teaching and learning of mathematics in the classroom is to engage the students with many activities and take home assignments that will intrigue the use of critical thinking and rational reasoning in solving them. Mathematics when properly taught to students may help to enthuse and generate critical thinking and rational reasoning in them which may be very useful in solving future problems for social and economic development.

\section{Conclusion}

In order that mathematics education should be used as an avenue for recovery of human values for social and economic development in Nigeria, parents, teachers and educational stakeholders should be deeply involved. The implication is that parents assuming full responsibility of the education of their children and not leaving it solely on the hands of teachers and the school authorities will enhance socio-economic development in Nigeria. Again, teachers being dedicated and committed to their teaching practices in the classroom will enhance mathematics education. All the educational stakeholders including federal and states, ministries of education and school authorities providing necessary resources for teaching and learning of mathematics in the classroom will go a long way to enhance effective teaching/learning of mathematics in the classroom. Obviously mathematics teachers may be in a better position to inculcate properly in the students mathematics concepts in a way it may actually discipline the minds and develop in

\section{Volume 4 Issue 11, November 2015}




\section{International Journal of Science and Research (IJSR) \\ ISSN (Online): 2319-7064 \\ Index Copernicus Value (2013): 6.14 | Impact Factor (2014): 5.611}

them the spirit of critical thinking and rational reasoning towards problem-solving in the society and Nigeria at large. For example, in this era of massive unemployment in the country, with critical thinking and rational reasoning one can create and originate a job for oneself and accrues revenue for oneself. Though critical thinking one can even be a job creator and employer of labour, which is highly beneficial for socio-economic development of a country. In view of all these, the following recommendations are made.

\section{Recommendations}

1) In order to recover the minds of the young ones and the youths towards hard work/diligence, problem-solving and self-discipline, families, schools and society at large have great roles to play.

2) In the family, parents should go back to early formation of their children by engaging them in doing those tasks that involve critical thinking and rational reasoning in solving them such as sending them market to purchase some items, cooking, taking decisions and budgeting. Parents again, should engage their children early enough in mental arithmetic which may help them in developing the spirit of critical thinking towards problem-solving.

3) In school, teachers should try to engage students with mental arithmetic and intriguing questions in mathematics that will elicit critical thinking in finding solution to problems.

4) The school authorities should encourage teachers towards effective mathematics education by paying them regular supervision and giving incentives to the best teachers.

5) The society at large both the governments and lovers of education should join hands to provide fund and resources to enthuse effective teaching and learning of mathematics in the classrooms for social and economic development in Nigeria.

\section{References}

[1] Agonga, O. (2011). Economic transformation through value reorientation. Punch Newspaper, $9^{\text {th }}$ December.

[2] Agwagah, U.N.V. (2005). Teaching mathematics for critical thinking, essential skill for effective living. Abacus: The Journal of the Mathematics Association of Nigerian (MAN) 30(1); 38-45.

[3] Awodeyi, A.F. (2004). Mathematics for sustainable development, implications and illustration for secondary education. Abacus: The Journal of MAN 2(1); 49-51.

[4] Fafunwa, A.B. (1982). History of Education in Nigeria.

[5] Federal Republic of Nigeria (2004). National Police on Education, Lagos NERDC, Press ( $3^{\text {rd }}$ Edition).

[6] Grain of Peace Value (2010). The 3 key concepts of grains of peace human values. www.graines-de-paizorglil/layout/set/pr.

[7] Harbour-Peters, V.F.A. (2000). Mathematics language for the new millennium: Implication to the society. $37^{\text {th }}$ Annual Conferences of Mathematics Association of Nigeria.

[8] Kolawole, E.B. and Oluwatayo, J.A. (2005). Mathematics for everyday living: Implication for
Nigeria secondary schools. Abacus: The Journal of the

Mathematical Association of Nigeria 30(1); 52-57.

[9] Moore, C. (2003). The role of mathematics and computer science in a development economy, In V.I.E. Ajiwe (ed). Progress in Science and Technology through General Studies. Adson Educational Publishers.

[10] Moore, C. (2005). Mathematics for critical thinking. The "Mathematicus", A publication of Mathematical Association of Nigeria (MAN), Anambra State Chapter, 1-6.

[11] Nwamaradi, A.T. (2005). Mathematics in action: the loss of autonomy. The "Mathematics" A publication of MAN, Anambra State Chapter, 39-47.

[12] Nwobi, E. (2015). Making sense of our education system. Interpress, Lagos-Nigeria, International News Bulletin, 104: 5-7.

[13] Okoye, U.C. (2011). Nigeria needs moral regeneration. http://www.ngrguerdiannews.com

[14] Onwudinjor, M.C. and Onwudinjor, O.E. (1999). Methods of Teaching Mathematics in Post Primary Institutions, 1-2.

[15] Parankimalil, J. (2012). Meaning, nature and aims of education. https://johnparankimalil/.wordpress.com

[16] Salau, M.O. (2002). Strategies for sustaining mathematics as an indispensible tool for sustainable technological development in the $21^{\text {st }}$ century. Proceedings of the $43^{\text {rd }}$ Science Teachers Association of Nigeria Annual conference and Inaugural Conference of CASTME Africa, 350-353.

[17] Steriner, R. (2012). Human values in education. wn.rserchive.org/...index.html

[18] Taiwo-Obalonye, J. (2015). Boko haram, Buhari gives services chiefs 3 months ultimatum. Daily sun Newspaper Friday $14^{\text {th }}$ August, 5. 